ments of technique, ${ }^{11}$ and the operative mortality (approximately $5 \%$ ) is similar to that of other methods.

The ideal method of endocrine ablation is not yet known. But carefully controlled comparative clinical trials are already in progress in some of the major centres concerned with this problem.

Despite the many methods of treatment now available, there is no rational plan for the management of patients with advanced breast cancer. A. P. M. Forrest, ${ }^{7}$ surveying 211 patients, found that most of them had received at least three different forms of treatment and that $25 \%$ had received five or more. The order in which treatments were given followed no definite pattern. As the rate of response to any form of treatment is low, many surgeons prefer to use major endocrine ablation as a last resort after simpler methods-the administration of hormones-have failed. But during hormone therapy many patients either die or become so ill that major ablation is out of the question. In one series a third of the patients died while taking hormones ${ }^{12}$; in another series $43 \%$ became unfit for major ablation while receiving treatment with androgens. ${ }^{13}$ In spite of this the results of three prospective clinical trials suggest that, from the point of view of survival, there is no advantage to be gained from early endocrine ablation, ${ }^{41415}$ and as the morbidity from simple forms of treatment is less than that from major ablation it seems reasonable at present to reserve major surgery until simple methods have failed. Oophorectomy in premenopausal women, or oestrogens (stilboestrol or ethinyl oestradiol) in postmenopausal women, may be followed at a later stage by whichever form of major ablation is most readily available.

In each of these three prospective trials fewer than $30 \%$ of the patients showed clear objective evidence of response. The corollary is that some $70 \%$ of them were subjected, unnecessarily, in the terminal stages of their illness, to unpleasant forms of treatment which proved to be of no value to them. Patients who respond to treatment obtain a remission which lasts on average for 18 months to two years and occasionally for five years or even longer. ${ }^{16}$ Pain from osseous metastases is relieved, lytic lesions recalcify, and pathological fractures may heal. When endocrine ablation is effective it brings dramatic relief, bedridden women may return to a normal way of life, and when they relapse finally death is usually

1 Huggins, C., and Bergenstal, D. M., Cancer Res. 1952, 12, 134.

2 Luft, R., and Olivecrona, H., 7 . Neurosurg., 1953, 10, 301.

$s$ Edelstyn, G. A., Gleadhill, C. A., Lyons, A. R., Rodgers, H. W., Taylor, A. R., and Welbourn, R., B., Lancet, 1958, 1, 462.

Atkins, H. J. B., Falconer, M. A., Hayward, J. L., MacLean, K. S., Schurr, P. H., and Armitage, P., Lancet, 1960, 1, 1148 .

Schurr, P. H., and Armitage, P., Lancet, Lancet, 1955, 1, 1054.

- Forrest, A. P. M., and Brown, D. A. P., Lancet, 195, , 1, 1054., R. E., Lancet, 1959, 1, 382 .

'Forrest, A. P. M., f. roy. Coll. Surg. Edinb., 1967, 12, 192.

8 Westover, J. L., Rand, R. W., and Greenfield, M. A., Radiology, $1960,74,86$.

9 James, J. A., Brit. med. F., 1962, 2, 332.

10 Reed, P. I., and Pizey, N.C. D., Brit. F. Surg., 1967, 54, 369.

11 Harrold B. P. Cates, J. E., and James, J. A., Brit. F. Cancer, 1968,

12 Atkins, H., Falconer, M. A., Hayward, J. L., MacLean, K. S., and Atkins, H., Falconer, M. A., Hayward,

Schurr, P. H., Lancet, 1966, 1, 827.

13 Dao, T. L., and Nemoto, T., Surg. Gynec. Obstet., 1965, 121, 1257. ed. Forrest A. P. M., and Kunkler, P. B. 1968. Edinburgh.

15 Sellwood, R. A., Davey, J., Galasko, C. S. B., Li, J., and Burn, J. I., Brit. F. Surg., 1968, 55, 870.

16 Welbourn, R. B., Ann. roy. Coll. Surg., 1967, 41, 131.

17 Juret, P., Prognostic Factors in Breast Cancer, p. 393, ed. Forrest, A. P. M., and Kunkler, P. B. 1968. Edinburgh.

18 McCalister, A., et al., Brit. med. F., 1961, 1, 613.

19 Nemoto T., and Dao, T. L., Cancer (Philad.), 1966, 19, 421.

20 Bulbrook, R. D., Greenwood, F. C., and Hayward, J. L., Lancet, 1960, 1, 1154 .

${ }^{21}$ Fotherby, K., Sellwood, R. A., and Burn, J. I., Brit. F. Surg., 1968, 55. 769.

22 Atkins, Sir H., et al., Lancet, 1968, 2, 1255.

23 Atkins, Sir H., et al., Lancet, 1968, 2, 1261. swift. But a method is needed greatly to distinguish those patients who are likely to respond to treatment from those who are not.

Certain factors are known to influence the patient's response. These include the latent interval between treatment of the primary disease and the appearance of metastases, the sites of the lesions, the relation to the menopause, the response to previous endocrine therapy, and the amounts of certain steroid hormones excreted in the urine. Patients with a long latent interval are more likely to respond to endocrine ablation than those with a short one. ${ }^{11} 17$ Visceral deposits, particularly those of brain, lung, and liver, seem less likely to regress than skeletal ones. ${ }^{11} 1819$ Premenopausal women fare better than postmenopausal women and those within five years of the menopause fare worst of all. Major ablation is likely to be particularly effective in premenopausal women who have responded previously to oophorectomy. R. D. Bulbrook and his colleagues ${ }^{20}$ studied the amounts of various urinary steroids excreted by patients with advanced cancer of the breast who were subsequently treated either by adrenalectomy or by hypophysectomy. They found that in those patients who tended to benefit from operations the urinary levels of aetiocholanolone were high and the levels of total 17-hydroxysteroids were low. Conversely, if aetiocholanolone was low and the 17-hydroxysteroids were high patients were unlikely to respond. In order that these estimations could be used for purposes of prediction they combined them in a formula termed a "discriminant function." The formula was 80-80 (17-OHS (mg./24 hrs.)) + aetiocholanolone ( $\mu$ g. $/ 24$ hrs.). When the preoperative levels of the steroids were substituted in the formula and the result was a positive number, a successful response to operation was likely. If it was negative, an operation was likely to fail. These estimations are tedious to perform and require a skilled steroid chemist, but results from several other centres appear to confirm those of Bulbrook and his colleagues, ${ }^{16}{ }^{21}$ and the subject merits a more detailed study. Recent work suggests that the discriminant function may predict the response to hypophysectomy more effectively than that to adrenalectomy. ${ }^{22} 23$

None of the factors mentioned or any combination of them enable us, at present, to predict for certain whether any individual patient will respond to ablation or not. Before we can answer the question, "What is the place of hypophysectomy in the treatment of breast cancer?" we need more prospective comparative clinical trials, more fundamental studies of the endocrine status of the patients, and a detailed discriminant analysis of the many factors which may influence response.

\section{Screening for Inborn Errors of Metabolism}

The term "screening" is commonly used to describe the investigation of a group of apparently healthy people for specific diseases. A screening procedure should be relatively simple and inexpensive, should give no false negative and few false positive results, and should detect a disease for which early treatment has value. Economic, social, and ethical

1 Screening for Inborn Errors of Metabolism. Report of a WH.O. Scientific Group. Wld Hlth Org. techn. Rep. Ser., 1968, No. 40 !. 8s. net. 
problems, both national and personal, must also be considered even though these are very complex. In no society are the resources available for health services unlimited. It has in fact been estimated that it is cheaper to keep a child with phenylpyruvic amentia in a mental hospital than to have a screening programme to detect this one child and to treat it ; and the keeping alive of a child with maple syrup urine disease (at great expense) may perpetuate a deleterious gene. Screening can be carried out by biochemical tests, as for diabetes mellitus and phenylketonuria ; by radiology, as for tuberculosis and lung cancer ; by cytology, as for carcinoma of the cervix ; and in many other ways, whether clinical or laboratory.

Screening may also be the performance of a group of predetermined tests (usually biochemical) on healthy or sick persons in the hope of finding an undiagnosed and treatable abnormality. Such unsuspected findings as hypercalcaemia may be detected, though experience has shown that despite thorough and expensive investigations the ultimate cause of the abnormality may not be found. We may have to reconsider our view of the normal and abnormal in the light of the data obtained by multichannel biochemical analysers and computer sorting of the vast number of results that they produce.

The World Health Organization has recently brought out a report ${ }^{1}$ on screening specifically for inborn errors of metabolism. It is compiled by a distinguished international panel under the chairmanship of Dr. A. G. Bearn, of the department of medicine at Cornell. An illuminating introduction deals with the general principles of screening for metabolic diseases. The diseases described fall into three main classes (diabetes mellitus is omitted), and the panel reviews for each what is known of its frequency, genetics, natural history, detection, and treatment. The diseases are as follows: (a) Welldefined inborn errors of metabolism-phenylketonuria, tyrosinaemia, maple syrup urine disease, some other amino-acid disorders, galactosaemia, and Wilson's disease. (b) Metabolic errors of pharmacogenetic importance-the porphyrias, pseudocholinesterase abnormalities. (c) Selected metabolic disorders (in brief), whose qualifications for entry are more doubtful-adrenogenital syndrome, pancreatic cystic fibrosis, muscular dystrophy, Hurler's syndrome. Techniques for screening for amino-acid disorders, galactosaemia, caeruloplasmin deficiency, the porphyrias, and abnormal pseudocholinesterases are described in variable detail.

This report deserves to be read by everyone concerned either with the setting up of screening programmes or with the diagnosis and management of the diseases described.

\section{Holmes-Adie Syndrome}

A variety of eponyms have been bestowed on the benign condition "simulating tabes dorsalis" usually called the Holmes-Adie syndrome. ${ }^{1}$ The suggestion has now been made that Holmes's ${ }^{5}$ name be omitted on the grounds that he had "said that the pupils were always fixed to light.". This objection may perhaps be countered with the argument that Holmes gave in his paper ${ }^{3}$ a particularly graphic description of the "tonic" pupil:

"Frequently no change in the size of the pupil was visible immediately on convergence, but when this was maintained for a few seconds the pupil slowly and gradually grew smaller, till its diameter equalled or was even narrower than that of the normal eye. The rate of contraction varied very much in different cases. When contracted the pupil remains constant and when convergence is relaxed it dilates slowly."

Frequently such tonic pupils do not react to light, and the tonic reaction shown in response to light after a period of dark adaptation is found to be excited by the " near" rather than by the "light" reflex.

Another type of pupillary abnormality in the Holmes-Adie syndrome is paralysis with mydriasis. It seems to have escaped medical historians that one of the earliest clinical accounts of this syndrome with a "paralytic" pupil of this kind was given by Hughlings Jackson ${ }^{4}$ in 1881:

"A woman aged 26 was sent to me simply because the right pupil was much larger than the left. It had been so for three years ... the pupil was dilated and absolutely motionless to light and accommodation, yet the accommodation itself on this side was perfect ... this case at first puzzled me. She seemed to me, and was, in perfect health, except for the ocular abnormalities. It occurred to me to test her knees. I could not find the smallest trace of the knee phenomenon."

Only since the discovery of the Wassermann reaction in 1906 has it become possible to establish that the HolmesAdie syndrome was of non-luetic nature, and $\mathrm{H}$. Oloff was among the first to describe a tonic pupil with loss of knee jerks in a youth aged 18 whose blood and cerebrospinal-fluid Wassermann reactions were negative. ${ }^{5}$

In 1940 H. G. Scheie ${ }^{6}$ noted that, whereas the tonic pupil contracted when $2.5 \%$ solution of methacholine was instilled into the conjunctival sac, the normal pupil failed to respond to the drug in this concentration. In view of this hypersensitivity of the tonic pupil to an acetylcholine-like substance he postulated a lesion of the parasympathetic postganglionic fibres. This inference was recently confirmed by D. G. F. Harriman and $H$. Garland, who found extensive neurone degeneration in the ciliary ganglion of the eye which during life showed tonic pupillary reactions. ${ }^{2}$ Similar observation had been previously reported by F. Ruttner. ${ }^{7}$ That the topography of neuronal loss in the Holmes-Adie syndrome is within the parasympathetic outflow of the autonomic system is also supported by those rare cases in which this syndrome is associated with segmental sudomotor denervation. ${ }^{8}$ This localization of the neuronal degeneration serves to differentiate Holmes-Adie syndrome from a number of other disorders of the autonomic system. ${ }^{9-11}$

Scheie further suggested that the tonic reaction of the pupil could best be explained by the diffusion of acetylcholine from the surviving parasympathetic nerve endings to the denervated endings, known to be hypersensitive. If the number of surviving parasympathetic postganglion fibres is insufficient, the tonic reaction will be abolished. Such fixed dilated pupil may, however, still contract slowly, on lacrimation. ${ }^{12}{ }^{13}$

1 Adie, W. G., Brit. med. 7., 1931, 1, 928.

2 Harriman, D. G. F., and Garland, H., Brain, 1968, 91, 401.

3 Holmes, G., Trans. ophthal. Soc. U.K., 1931, 51, 209.

- Jackson, J. H., Trans. ophthal. Soc. U.K., 1881, 1, 151.

5 Oloff, H., Klin. Mbl. Augenheilk., 1914, 53, 493.

Scheie, H. G., Arch. Ophthal., 1940, 24, 225.

Ruttner, F., Mschr. Psychiat. Neurol., 1947, 114, 265.

Esterly, N.' B., Cantolino, S. J., Alter, B. P., and Brusilow, S. W., f. Pediat, 1968, 73, 852 .

Solitare, G. B., and Cohen, G. S., Neurology (Minneap.), 1965, 15,

10 Johnson, R. H., Lee, G. T., Oppenheimer, D. R., and Spalding, J. M. K., Quart. F. Med., 1966, 35, 276.

1 Schwartz, G. A., Arch. Neurol., 1967, 16, 123.

12 Graveson, G. S., F. Neurol. Neurosurg. Psychiat., 1949, 12, 219.

13 Russell, G. F. M., F. Neurol. Neurosurg. Psychiat., 1956, 19, 289.

14 Hardin, W. B., and Gay, A. J., Neurology (Minneap.), 1965, $15,613$.

is Rudolph. G. de M., F. Neurol. Psychopath., 1936, 16, 367.

16 Hough, iv. H., Med. Ann. D.C., 1941, 10, 137 .

17 Hedges, T. R., jun., Arch. Ophthal., 1968, 80, 21. 